\title{
Synchronization of Solar Stand-alone Devices and Autonomous Energy Management through Solar Time Measurements
}

Santamaria Lancia, Adrian Alejo; Riedel, Nicholas; Ploug, Rasmus Overgaard; Thorsteinsson, Sune; Poulsen, Peter Behrensdorff; Benatto, Gisele Alves dos Reis

\section{Published in:}

Proceedings of 7th World Conference on Photovoltaic Energy Conversion

Link to article, DOI:

10.1109/PVSC.2018.8548183

Publication date:

2018

Document Version

Peer reviewed version

Link back to DTU Orbit

Citation (APA):

Santamaria Lancia, A. A., Riedel, N., Ploug, R. O., Thorsteinsson, S., Poulsen, P. B., \& Benatto, G. A. D. R. (2018). Synchronization of Solar Stand-alone Devices and Autonomous Energy Management through Solar Time Measurements. In Proceedings of 7th World Conference on Photovoltaic Energy Conversion (pp. 0632 0637). IEEE. https://doi.org/10.1109/PVSC.2018.8548183

\section{General rights}

Copyright and moral rights for the publications made accessible in the public portal are retained by the authors and/or other copyright owners and it is a condition of accessing publications that users recognise and abide by the legal requirements associated with these rights.

- Users may download and print one copy of any publication from the public portal for the purpose of private study or research.

- You may not further distribute the material or use it for any profit-making activity or commercial gain

- You may freely distribute the URL identifying the publication in the public portal 


\title{
Synchronization of Solar Stand-alone Devices and Autonomous Energy Management through Solar Time Measurements
}

\author{
Adrián A. Santamaría Lancia ${ }^{1}$, Nicholas Riedel ${ }^{1}$, Rasmus Overgaard Ploug${ }^{2}$, Sune Thorsteinsson ${ }^{1}$, Peter \\ Behrensdorff Poulsen ${ }^{1}$, Gisele A. dos Reis Benatto ${ }^{1}$ \\ ${ }^{1}$ Technical University of Denmark, Department of Photonics Engineering, Frederiksborgvej 399, 4000 \\ Roskilde, Denmark. Tel: +45 46774572. E-mail: ppou@fotonik.dtu.dk \\ ${ }^{2}$ Technical University of Denmark, Department of Electrical Engineering, Elektrovej, B325, 2800 Kgs. \\ Lyngby, Denmark
}

\begin{abstract}
This works present a method for synchronization of a solar device to real solar time for event triggering and energy management. Specifications require the devices to be off-grid and self-adjusting. Measurements of daylight duration were performed using one test device over the course of several months in Denmark. Analysis of viability over the accuracy of solar time determination and potential for self-adjusting energy management was carried out. Measurement results allowed for the development of an algorithm with good potential for performing the required tasks. Influence of variations in weather and different shadowing conditions were tested in two prototype devices. Results show a good potential for daily synchronization between devices and estimation of solar time within less than 5 minutes error.
\end{abstract}

\section{INTRODUCTION}

One of the market possibilities for photovoltaic devices is within innovation in product development. The department of Photonic Engineering of the Technical University of Denmark (DTU) works closely with partners in the industry developing solar-powered electronic systems for diverse leisure activities and outdoor illumination products (Product Integrated PV). These products involve a small solar panel or array of solar cells used to provide energy for charging the battery and powering the application. Examples of the devices embedded in such products are bluetooth connectivity for cellphones, speakers for music playing, charging of cellphones and laptops, LED illumination, among many others.

The project, called 'Solar Clock' for short, started as a collaboration with one of our partners, in order to improve the manufacturing and distribution of one of their products. The product in question is a solar powered, LED illuminated, battery powered off-grid lamp post for outdoors installation. The power consumption of this product is adjusted to the available energy in the battery and thus the lights are dimmed according to the energy in the battery, the length of the dark period and a history based prediction of the incoming energy. A dimming scheme was incorporated within the electronics for each month of the year, and five intervals during the 24 hours of the day. As it has been manufactured so far, our partner has first to receive a purchase order from their customer to know in which location the products are to be installed and their quantity. The required PWM adjustment for energy management was determined according to some estimation of the solar resource available on the location and each table was programmed in each product individually in factory before shipping. This process is costly and very time consuming.

To improve this situation stablished the requirements of the Solar Clock. A self-learning algorithm that can estimate the solar time of each day for synchronization purposes and it is able to measure the current daylight duration and make predictions for future daylight durations in order to correct in real time the energy management parameters without human intervention. Another requirement is robustness of the algorithm against shadowing/other environmental effects.

An accurate measurement of daylight duration with a photovoltaic device as a sensor would provide information about daylight duration for each day [1]. The electronic device used as control possess an oscillating clock that would measure the duration of daylight with high resolution. The duration of daylight (DD) between consecutive days can be compared and the difference in daylight duration $(\Delta \mathrm{dd})$ can be stablished. This could allow the algorithm to predict if the days are getting shorter or longer and adjust the energy management settings accordingly. Furthermore, the sun trajectory over the sky over the course of the year and for every location has been determined in a set of astronomical equations that can be used for accurate predictions.

\section{METHODS}

The approach used in this work required thorough understanding of the sun position astronomical equations, selecting an appropriate measured variable and understanding the environmental effects that influence the measurements.

For performing this part of the study, the open circuit voltage $\left(\mathrm{V}_{\text {oc }}\right)$ was measured in intervals of 10 seconds on two solar panels embedded in LED lampposts placed in our Risø outdoor PV test facilities. The solar panels are facing upwards in the sky. The lamps are named TS08 and TS09 and both are similar in specifications to the product manufactured by our partner. They include LEDs, battery and control/charge electronics.

A. Voc as Measured Parameter 
When a photovoltaic device is used as a sensor, normally its main goal is to measure irradiance through its short circuit

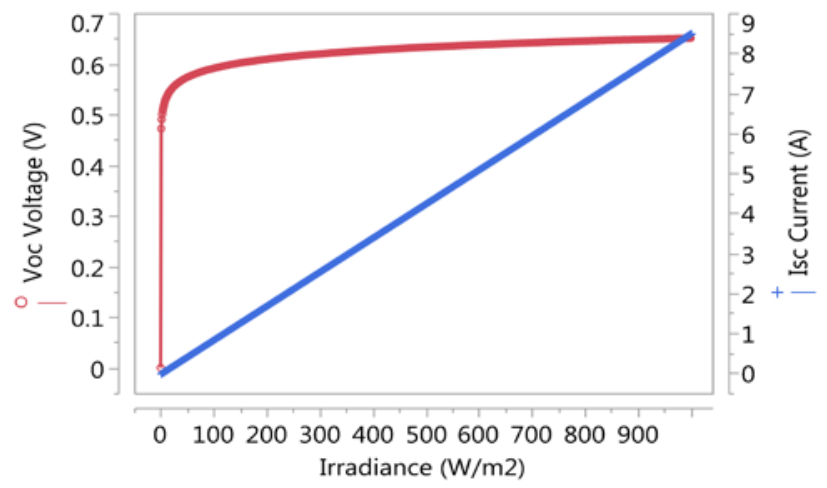

Fig. 1. Dependence of $\mathrm{V}_{\mathrm{oc}}$ and $\mathrm{I}_{\mathrm{sc}}$ with irradiance.

current $\left(\mathrm{I}_{\mathrm{sc}}\right)$. This is under the assumption of linearity of the device with irradiance, which is a good assumption for silicon PV devices. Irradiance during the day, however, is strongly influenced by environmental factors like clouds, shadows on the device, other illumination sources, etc. and it does not constitute a useful parameter. The $\mathrm{V}_{\text {oc }}$ has a logarithmic dependence with irradiance and it has been tested to provide excellent sensitivity at low irradiance values, as illustrated in Figure 1. It is able to detect sunrise and sunset diffuse light, and remain at a high, almost constant value until the irradiance level drops down significantly.

Measured values of $\mathrm{V}_{\text {ос }}$ are corrected for temperature using a temperature/humidity sensor located close to the lamps location.

A study about the suitability of $\mathrm{V}_{\text {ос }}$ as $\mathrm{DD}$ measurement parameter has been performed. Global Horizontal Irradiance (GHI) has been recorded simultaneously with $\mathrm{V}_{\text {oc }}$ measurements performed on 36 cells, multi-Si modules positioned at the same angle as the sensor. This data shows that irradiance is not always zero before sunrise or after sunset, but is observed to be as high as $10 \mathrm{~W} / \mathrm{m}^{2}$ when the sun is below the horizon and this level of ambient light is enough to turn on the $\mathrm{PV}$ voltage. The mean response time of $\mathrm{V}_{\text {oc }}$ for these modules has been measured to be around $13 \mathrm{mV} / \mathrm{sec}$ for the turn on slope and $-15 \mathrm{mV} / \mathrm{sec}$ the turn off slope. Both $\mathrm{V}_{\text {ос }}$ response time and sensitivity to irradiance are more than adequate.

\section{B. Sun Position Studies}

Out of the solar equations studied, the most important is the one that relates the Duration of Daylight (DD) with the declination $(\delta)$ and the latitude (L) of the location.

$$
\cos \left(\frac{\pi D D}{24}\right)=-\tan \left(\frac{\pi L}{180}\right) \times \tan \left(\frac{\pi \delta}{180}\right)
$$

This equation and the calculations and assumptions made for the development of this algorithm are valid for latitude values between $-65^{\circ}\left(65^{\circ} \mathrm{S}\right)$ and $+65^{\circ}\left(65^{\circ} \mathrm{N}\right)$.

The declination of the earth towards the Sun is an angle whose value that changes between the values of $-23.45^{\circ}$ to $23.45^{\circ}$ over the course of 6 months and going back to $-23.45^{\circ}$ during the remaining 6 months of the calendar year.

This is what produces the change in seasons during the year. There are four days during the calendar year that mark the beginning and end of the seasons. These are the winter and summer solstices and the autumn and spring equinoxes. The winter and summer solstices the longest and shortest daylight duration of the year respectively, and the minimum $\Delta \mathrm{dd}$ within neighboring days.

The characteristics of these days that are directly measurable by the voltage of a photovoltaic sensor are the Daylight Duration (DD) and the Difference in Daylight Duration between the few previous and following days $(\Delta \mathrm{dd})$. Both parameters are different in value depending on the Latitude, but follow the same pattern in all locations regarding their properties during the solstices and equinoxes.

The duration of daylight has a unique value for each day of the year and each latitude value regardless being $\mathrm{N}$ or $\mathrm{S}$ (or \pm L). In opposite latitudes, the same daylight duration occurs in different days of the year.

If it would be possible to measure the daylight duration of a single day with an error of less than 3 minutes and 20 seconds, then the Latitude can be obtained after either one of the Solstices occur. This error value is smaller than the smallest difference of daylight duration between two consecutive latitudes (3 minutes 28 seconds at the equator).

If the Latitude of the location can be obtained, then it would be possible to predict accurate future DD values calculating them from the astronomical equation.

\section{Measurements Performed}

Measurements of $\mathrm{V}_{\text {ос }}$ were performed on both TS08 and TS09 lamps for several months in 2017 and it is currently ongoing at the time of this manuscript writing.

Since the solar panel in both lamps are connected to the battery charger controller, the measurements values over the course of a day contain many fast and significant variations, which mainly correspond to switching of the electronic device and battery voltage levels when $\mathrm{V}_{\text {batt }}$ differs from Voc.

In order to assess the accuracy and environmental effects over the daylight duration, the control electronics was turned off on TS08 and the panel of this device was left in permanent open circuit mode. Measurements were performed in these conditions during Denmark's winter solstice and the time of this writing. This time interval represents the minimum difference in daylight duration between consecutive days, and could provide a good test of the resolution of the device. 


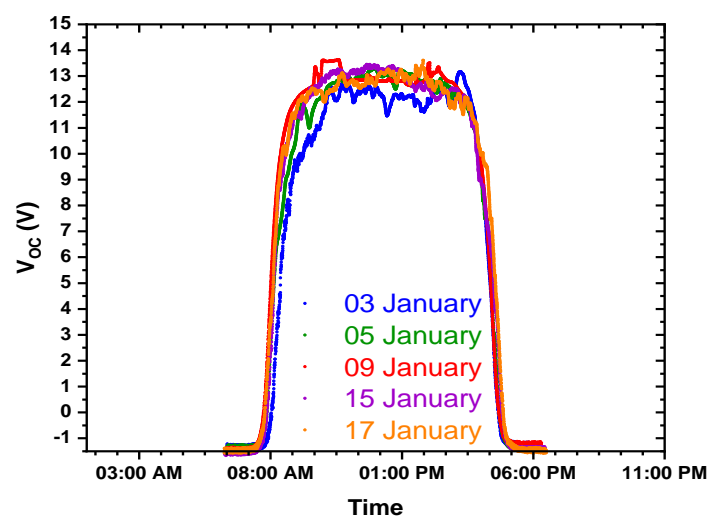

Fig. 3. Measurements of $\mathrm{V}_{\text {ос }}$ showing changes in daylight duration after the Winter Solstice.

As it can be observed in Fig. 2, weather conditions such as cloudiness can affect the shape of the slope and the flat zone of the $\mathrm{V}_{\text {oc }}$ measurement. Measurements performed in different days would either yield a smoother slope or a more irregular one. During these days, the daylight duration calculation can deviate significantly from the theoretical one, and the previously measured ones. These could be marked as outliers when determining sunset/sunrise times.

A proper selection of threshold voltage values to generate the detection of a sunrise and sunset event is also very important parameter that can affect the daylight duration measurements and were studied with new devices deployed in our campus at Risø.

\section{Sunset and Sunrise point determination}

The rise/decrement slope of $\mathrm{V}_{\text {oc }}$ has a duration over time that can take close to 25 minutes to rise from $0 \mathrm{~V}$ to $60 \%$ of Voc. Afterwards, the curve begins to stabilize to the $\mathrm{V}_{\text {oc }}$ maximum value. For the algorithm to work, it must be able to select a point of the curve every day for both sunset and sunrise slopes, in which the day duration interval is consistent when comparing the days with each other. One method was developed, in which 5 points of each slope were measured and a median value was taken to mark the sunset (or sunrise) point.

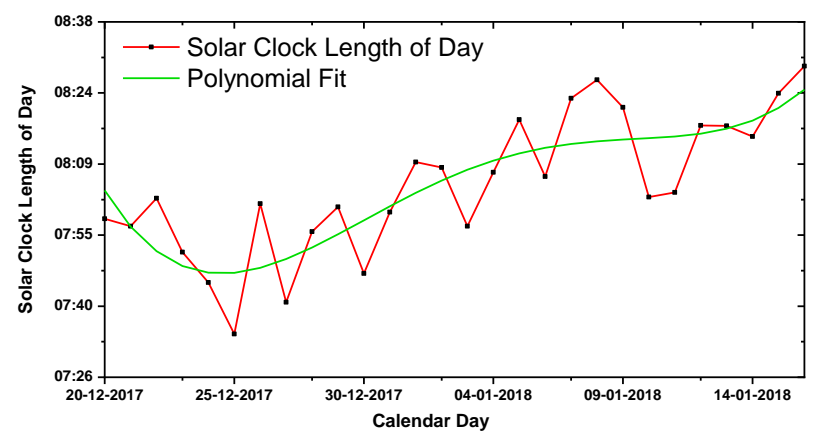

Fig. 2. Measurements of daylight duration for 10 consecutive days and polynomial fit. Improvement can be made removing outliers.
The values of DD calculated with this method were compared between consecutive days and it is shown in Fig. 3.

It can be seen that the dispersion between individual daylight durations is significant and can reach differences beyond 25 minutes in certain cases. However, they do follow the tendency of increasing in value after the winter solstice, which correspond with the daylight hours increasing by each passing day towards the summer.

\section{E. Daylight Duration Measurement under Different Environmental Conditions.}

Three measurement devices were constructed to evaluate the performance of the daylight duration measurement under different environmental conditions. Each device consisted of a photovoltaic 3 Volts DC, 250mA PV mini-module, a Texas Instrument programming board for an MSP432P401 microcontroller and a battery pack to power the board under stand-alone conditions. All the electronics were enclosed in a weather resistant box with the solar panel attached facing up on the top cover. The battery pack allowed for an autonomy of only 4 days of measurement, due to the consumption of the JTAG programming interface of the board, which also provides regulated $3.3 \mathrm{~V}$ to the microcontroller. Disabling this part of the board would have produced substantial consumption drop, however it was not possible to do this in a practical way. Measurements were performed in sets of 4 days and the data downloaded and analyzed in between.

The microcontroller was programmed to $\log$ the $V_{\text {oc }}$ of the photovoltaic panel and determine the daylight duration when the voltage level passed certain threshold value. Two threshold values of $1.0 \mathrm{~V}$ and $1.5 \mathrm{~V}$ were tested. Both levels were implemented with a $0.2 \mathrm{~V}$ hysteresis for 300 seconds period. This means that for the $1 \mathrm{~V}$ threshold, the behavior of the device from day to night is that it initialize counting the 300 seconds when PV voltage is beneath $0.9 \mathrm{~V}$ and it continues the counting as long as the PV voltage is beneath $1.1 \mathrm{~V}$. When the 300 seconds have passed it declares shift from day to night. The same process is repeated from night to day. Daylight Duration measurement for both levels were recorded.

Due to malfunction of Device 2, only two devices were deployed in three different locations. Device 1 was placed on top of the Fotonik building in Risø (where the Weather Station sensors that monitor irradiance conditions are installed, abbreviated WSt). This location has a completely unobstructed exposure to sunlight. Device 3 was placed against the wall of a neighbor building. The wall is facing West, and the device is completely under the shadow until the late afternoon (West Facade, abbreviated WFc). The Sunrise moment detected by this device will be due to diffuse light only. Finally, Device 3 was placed against a north oriented wall, having no exposure to direct light (Total Shadow, abbreviated TSw). Both sunrise and sunset points will be detected by diffuse light.

Device 1 and Device 3 were placed next to each other under unobstructed sunlight to compare their measurements under same conditions. The measurements in Daylight Duration of 
both devices had consistently a difference of 12 minutes maximum (Device 1 measures longer DD than Device 3). This is also true for both threshold levels. The cause for this particular difference is under study.

\section{ANALYSIS}

The resolution and inaccuracy of the photovoltaic device acting as a sensor, plus all environmental factors affecting the measurement of the daylight duration does not allow to obtain daylight duration values directly comparable in resolution with the calculated ones from the equations for every single day.

\section{A. Weather Dependence and Threshold Voltage Values}

For assessing the influence of weather conditions on the DD measurements, the measured values from Weather Station (Device 1) were compared to the ones obtained for each day of the year through astronomical equations, at the latitude of our Risø campus in Denmark (55.64 N approx.) as shown below.

TABLE I

Calculated values for the interval of days under study using Equation 1.

\begin{tabular}{|c|c|c|c|}
\hline Day & $\begin{array}{c}\text { Calculated } \\
\text { Daylight Duration } \\
\text { (Hours) }\end{array}$ & $\begin{array}{c}\text { Calculated Daylight } \\
\text { Duration (Minutes) }\end{array}$ & $\begin{array}{c}\text { Calculated } \Delta \text { dd } \\
\text { (Minutes) }\end{array}$ \\
\hline 20-Apr-18 & 14.25 & 854.8 & 4.51 \\
\hline 21-Apr-18 & 14.32 & 859.3 & 4.49 \\
\hline 22-Apr-18 & 14.40 & 863.8 & 4.47 \\
\hline \hline 04-May-18 & 15.26 & 915.5 & 4.15 \\
\hline 05-May-18 & 15.33 & 919.6 & 4.11 \\
\hline 06-May-18 & 15.39 & 923.7 & 4.08 \\
\hline 10-May-18 & 15.66 & 939.6 & 3.91 \\
\hline 11-May-18 & 15.72 & 943.4 & 3.86 \\
\hline 12-May-18 & 15.79 & 947.3 & 3.81 \\
\hline
\end{tabular}

TABLE II

Measured values of Daylight Duration. Device 1 is located in Weather Station and Device 3 in West Facade. Threshold values comparison from Device 1.

\begin{tabular}{|c|l|c|c|c|c|}
\hline Day & \multicolumn{1}{|c|}{$\begin{array}{c}\text { Weather } \\
\text { Conditions }\end{array}$} & $\begin{array}{c}\text { Weather } \\
\text { Station vs. } \\
\text { Calculated } \\
\text { (Minutes) }\end{array}$ & $\begin{array}{c}\text { West } \\
\text { Façade vs. } \\
\text { Calculated } \\
\text { (Minutes) }\end{array}$ & $\begin{array}{c}\text { Weather } \\
\text { Station } \\
\text { vs. West } \\
\text { Façade } \\
\text { (Minutes) }\end{array}$ & $\begin{array}{c}\text { Threshold } \\
1.0 \mathrm{~V}- \\
1.5 \mathrm{~V} \\
\text { (Minutes) }\end{array}$ \\
\hline 20-Apr-18 & $\begin{array}{l}\text { All day very } \\
\text { sunny }\end{array}$ & 57.6 & 38.5 & 19.0 & 16.3 \\
\hline 21-Apr-18 & $\begin{array}{l}\text { All day very } \\
\text { sunny }\end{array}$ & 61.8 & 43.2 & 18.6 & 15.8 \\
\hline 22-Apr-18 & $\begin{array}{l}\text { All day very } \\
\text { sunny }\end{array}$ & 60.0 & 40.4 & 19.6 & 14.7 \\
\hline 04-May-18 & $\begin{array}{l}\text { Cloudy } \\
\text { morning, sunny }\end{array}$ & 65.9 & 45.3 & 20.6 & 16.7 \\
\hline 05-May-18 & $\begin{array}{l}\text { Sunny with } \\
\text { few clouds }\end{array}$ & 67.7 & 47.2 & 20.5 & 16.0 \\
\hline 06-May-18 & $\begin{array}{l}\text { Al day very } \\
\text { sunny }\end{array}$ & 67.8 & 46.6 & 21.2 & 16.7 \\
\hline \hline 10-May-18 & $\begin{array}{l}\text { Very sunny, } \\
\text { rain in evening }\end{array}$ & 33.8 & 14.3 & N/M & 16.1 \\
\hline 11-May-18 & $\begin{array}{l}\text { Cloudy, } \\
\text { covered sky }\end{array}$ & 44.0 & 2.1 & N/M & 26.1 \\
\hline 12-May-18 & $\begin{array}{l}\text { Partially Sunny } \\
\text { and cloudy }\end{array}$ & 54.3 & 18.1 & N/M & 21.0 \\
\hline
\end{tabular}

Fig. 5: Daylight Duration measurements showing the effect of cloud sky in the voltage slope for the morning (11 of May) and late afternoon (10 of May and 12 of May). These weather effects produce an erroneously shorter DD.

Design of an appropriate threshold level has also influence on how close the measured values are to the calculated ones. Figure 6 shows the TS08 voltage curve and calculated Solar Elevation Angle for 22 ${ }^{\text {th }}$ of April and at the Risø campus location. The voltage slopes are produced with enough intensity 
of diffuse light in the sky, since at these times the sun is still below the horizon.

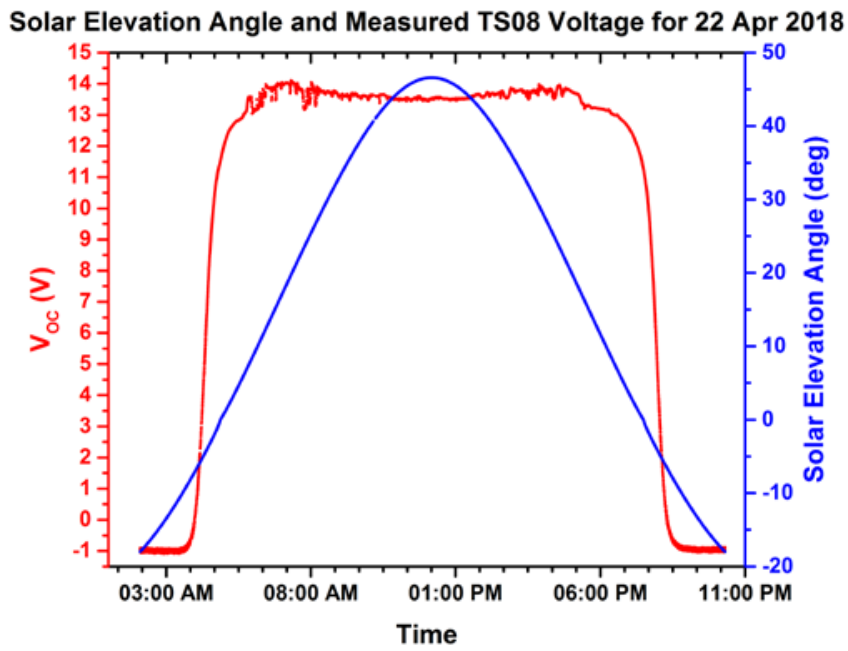

Fig. 6: Daylight Duration measured and calculated Solar Elevation Angle for Risø site. The voltage slopes occur when the sun has less than $-5^{\circ}$ elevation angle (it is below the horizon). The presence of diffuse light alone produces the desired voltage increment. The voltage threshold selection is a relevant parameter for comparison against calculated values.

For the Devices, the higher threshold value of $1.5 \mathrm{~V}$ produced DD values 14 to 17 minutes closer to calculated ones than the $1.0 \mathrm{~V}$ level under sunny conditions, though this cannot be taken as direct correlation. Further threshold levels should be tested to evaluate if better match to calculated values degrades or improve DD measurement performance due to other effects.

\section{B. Environmental Shadow Conditions}

Synchronization of the devices exposed under different conditions of light shadowing is an important parameter to be assessed from the industry point of view. Several devices placed inside the same location but under different light obstruction situations (trees, buildings, neighbor light sources) should be able execute the programmed tasks (e.g. switch on LEDs) at the same time or as close as possible. Some minutes delay between devices is acceptable for outdoors lightning.

Measured Daylight Duration (DD) was compared between Weather Station and the other two locations. It was shown that roughly 22 minutes difference exists with West Facade location under sunny conditions. The DD is measured to be shorter when the device loses exposure to direct incident light in the mornings.

A similar difference of 20 minutes was measured with the Total Shadow location under sunny days. However, on more cloudy days DD differences of a maximum of 42 minutes were measured in comparison with WSt values. This suggest that changes in weather conditions may increase even more the differences in measurements between devices under various shadow conditions.

\section{Effects on Devices Synchronization}

An estimation of the daily synchronization delay between devices should be considered to verify it is in acceptable range. The sources of deviations and the magnitude of their contributions have been evaluated. Measurement performed on the day $\mathrm{n}-1$ is used to determine the new 24-hour time duration for the current $\mathrm{n}$ day. This 24-hour interval is calculated as the summation of the DD measured on the previous n- 1 day and the night duration (ND) until the next sunrise detected on the $\mathrm{n}^{\text {th }}$ day. Midday and midnight are calculated as half the measured $\mathrm{DD}_{\mathrm{n}-1}$ and $\mathrm{ND}_{\mathrm{n}-1}$ values, and are stablished as zero points to which reference the amount of hours to trigger events. Comparison between the measured solar and the internal oscillation clock 24-hour intervals, allows obtaining daylight duration increment or decrement $(\Delta \mathrm{dd})$ for energy management and periodical internal synchronization adjustments.

In between consecutive days, the event triggering time will vary due to all effects studied in the $\mathrm{DD}_{\mathrm{n}-1}$ measurement. An event expected to be triggered at 18 hours solar time every day, will occur within a certain amount of minutes before or after, which will be different each day and per device.

Results from this study allow us to do some estimations about the total error per day that can be introduced. A worst-case scenario would be one with a very cloudy sky at sunset time on the day $n-1$, and very cloudy sky at sunrise time on the day n. These atmospheric effects make for an artificially shorter daylight duration, and their occurrence simultaneously would result in an inaccurately longer night duration. Assuming a detected sunrise 25 minutes later than in a sunny day (earlier for sunset), a total error in the 24-hour interval due to cloudiness only would be around 50 minutes.

As per the differences in DD between devices at the same position, which was found to be maximum 12 minutes, a conservative total of 20 minutes is assumed since only two devices were tested in this experiment and it cannot be taken as a maximum delay value at the moment.

Two devices under different shadow conditions could be expected to have an additional difference in DD measurement between 15 and 25 minutes.

These estimations and assumptions combined would introduce a total of 70 minutes increment between previous and current day calculation of the 24 hour interval, and a total of 45 minutes for devices under different shadowing conditions on the same day. This will introduce an error in event triggering time between consecutive days of almost 3 minutes, and between devices in the same day and weather conditions, the delay would be no more than 2 minutes. For our partner's purpose of synchronization or triggering of events regarding 
illumination in urban areas, this resolution for time measurement is acceptable.

\section{Energy Management}

Determination of $\Delta \mathrm{dd}$ to assess the amount of solar resource and predict future values is also possible. Day by day comparison yields unreliable information on whether DD is bigger or smaller than the previous day, but it does follow the season trend in intervals of a number of days. The number of days for each segment were chosen as 10 and measurements of DD for each of the days can be carried out. After the interval acquisition is finished, a polynomial fit is used to have an estimated interval total difference in daylight duration $\left(\Delta \mathrm{ddN}^{\mathrm{K}}\right)$ as shown in Figure 3. For the predicted difference in day duration for the next interval to be measured $\left(\mathrm{p} \_\Delta \mathrm{dd} 10^{\mathrm{K}}\right)$, a look-up table is used. This table will contain DD values for 10 days intervals during the year, and for each Latitude in steps of $1^{\circ}$. The algorithm will find the DD value closest to the fitted one obtained, and relate it to the Latitude. Then, the value from the table corresponding to the same latitude $\mathrm{L}$, but next interval of the year $\mathrm{k}+1$ will be selected. This value will be used in energy management to predict how much solar resource will be available, how long the night will be, and adjust the PWM for the LED

\section{CONCLUSIONS}

In this work, the effect of diverse weather and environmental conditions over the determination of duration of daylight have been studied. Despite the significant variations in measurements of daylight duration between devices in different locations, it is possible to estimate solar time for each day and implement synchronized events with an acceptable margin of error. This study suggest synchronization issues between devices and event triggering time in worst cases studied can amount to maximum 5 minutes. Future work should focus on obtaining more days of DD measurement to further validate these findings, and obtain more evidence of the correlation between the irregularities on the acquired curve and weather conditions. This can be achieved through the calculation of a diffuse ratio obtained from the weather station measurements. Prediction of solar resource and adjustment of energy management are also possible using intervals of few days. Additionally to the polynomial fit approach being considered to minimize the propagation of errors in the calculation of $\Delta \mathrm{ddN}^{\mathrm{K}}$, another possibility is to have part of the algorithm to analyze the shape of the $\mathrm{V}_{\text {oc }}$ curve and slopes produced during sunny days and cloudy days to determine outliers or produce an estimation of a true value. With further development aimed to increase understanding of environmental effects and reduce uncertainties, synchronization of stand-alone, self-adjusting photovoltaic devices to real solar time for event triggering and energy management shows great potential.

\section{REFERENCES}

[1] Simeon Lisovski, Chris M. Hewson, Raymond H. G. Klaassen, Fränzi Korner-Nievergelt, Mikkel W. Kristensen and Steffen Hahn, "Geolocation by light: accuracy and precision affected by environmental factors," Methods in Ecology and Evolution 2012, 3, 603-61 